\title{
PENCARIAN RUTE TERCEPAT TRANSPORTASI DI KOTA PADANG DENGAN ALGORITHMA DIJKSTRA
}

\author{
Musli Yanto, S.Kom, M.Kom \\ Teknik Informatika, Universitas Putra Indonesia "YPTK", Padang \\ Email : musli_yanto@upiypk.ac.id
}

\begin{abstract}
Abstrak
Begitu pentingnya sebuah informasi dalam kehidupan ini, membuat setiap orang berlomba mencarinya agar bisa tetap bertahan dan selamat dari kehidupan itu sendiri. Demikian juga bagi kalangan yang suka bepergian, informasi dipakai sebagai bahan analisa yang bertujuan untuk mendapatkan rute terpendek demi menghemat waktu, jarak tempuh dan sebagainya. Pencarian Rute dengan Algoritma Dijkstra merupakan salah satu cara untuk mencari rute tependek untuk mencapai tempat tujuan, sehingga nantinya bisa diketahui alternatif yang ada untuk menghemat waktu perjalanan, sehingga lebih cepat sampai ke tempat tujuan. Untuk pemgimplementasian pencarian rute tercepat, dipilihlah Kota Padang sebagai objek yang dikaji. Kota Padang yang terdiri dari beberapa kecamatan, desa dan kelurahan serta banyaknya percabangan jalan yang akan dilalui oleh pengendara motor dan mobil, baik bagi pendatang maupun daerah tetangga. Sehingga membuat pengendara banyak kebingungan dan tersesat sehingga memperlambat perjalanan menuju tempat tujuan
\end{abstract}

Kata kunci: Informasi, Algoritma Dijkstra, Alternatif dan Rute

\section{Pendahuluan}

Kemajuan ilmu pengetahuan dan teknologi pada saat ini sangatlah pesat dan sejalan pula dengan bertambah rumitnya dunia bisnis dan informasi, dan hal ini berpengaruh dalam kehidupan manusia. Salah satu diantaranya adalah munculnya peralatan yang disebut dengan komputer. Alat ini telah mampu menangani masalah proses pengolahan data menjadi informasi yang sangat diperlukan oleh para penggunanya. Namun dalam kehidupan ini permasalahan yang sering timbul disaat melakukan perjalanan dari satu daerah ke daerah lainnya membutuhkan waktu yang begitu lama dan kurangnya efisiensi waktu untuk berkunjung ke suatu daerah. Dengan memperoleh rute tercepat antara dua lokasi, maka tingkat efisiensi waktu yang dibutuhkan untuk melakukan perjalanan anatara dua lokasi tersebut akan lebih baik.

Untuk pemgimplementasian pencarian rute tercepat, dipilihlah Kota Padang sebagai objek yang dikaji. Kota Padang yang terdiri dari beberapa kecamatan, desa dan kelurahan serta banyaknya percabangan jalan yang akan dilalui oleh pengendara motor dan mobil, baik bagi pendatang maupun daerah tetangga. Sehingga membuat pengendara banyak kebingungan dan tersesat sehingga memperlambat perjalanan menuju tempat tujuan.

Berdasarkan latar belakang diatas, maka penulis dapat merumuskan permasalahan yang ada sebagai berikut :

1. Bagaimana merancang aplikasi untuk menentukan rute tercepat antar Kecamatan di Kota Padang dengan menampilkan beberapa alternatif awal?

2. Bagaimana merancang aplikasi dengan metode Algoritma Dijkstra dalam pencarian rute terpendek?

3. Bagaimana merancang aplikasi dengan mengimplementasikan Algoritma Dijkstra pada Java untuk pencarian rute tercepat? 


\section{Tinjauan Literatur}

\subsection{Rekayasa Perangkat Lunak}

Perangkat lunak adalah program komputer yang terasosiasi dengan dokumentasi perangkat lunak seperti dokumentasi kebutuhan, model desain, dan cara penggunaan (user manual). Sebuah program komputer tanpa terasosiasi dengan dokumentasinya maka belum dapat disebut perangkat lunak (software). Sebuah perangkat lunak juga sering disebut dengan sistem perangkat lunak. Sistem berarti kumpulan komponen yang saling terkait dan mempunyai satu tujuan yang ingin dicapai.

Sistem perangkat lunak berarti sebuah sistem yang memiliki komponen berupa perangkat lunak yang memiliki hubungan satu sama lain untuk memenuhi kebutuhan pelanggan (customer). Pelanggan (customer) adalah orang atau organisasi yang memesan atau membeli perangkat lunak (software) dari pengembangan perangkat lunak atau bisa dianggap bahwa pelanggan (customer) adalah orang atau organisasi yang dengan suka rela mengeluarkan uang untuk memesan atau membeli perangkat lunak. User atau pemakai perangkat lunak adalah orang yang memiliki kepentingan untuk memakai atau menggunakan perangkat lunak untuk memudahkan pekerjaannya (Rosa A.S dan M. Shalahuddin, 2013).

\subsection{UML (Unifted Modelling Language)}

Unified Modeling Language (UML) merupakan bahasa visual untuk pemodelan dan komunikasi mengenai sebuah sistem dengan menggunakan diagram dan teks-teks pendukung, UML hanya berfungsi untuk melakukan pemodelan. Jadi penggunaan UML tidak terbatas pada metodologi tertentu, meskipun pada kenyataanya UML paling banyak digunakan pada metodologi berorientasi objek (Rosa A.S dan M. Shalahuddin, 2013). Berikut ini diagram-diagram yang ada dalam UML (Rosa A.S - M. Shalahuddin, 2013) :

\section{a. Use Case Diagram}

Use case atau diagram use case merupakan pemodelan untuk kelakuan (behavoir) sistem informasi yang akan dibuat. Use case mendiskripsikan sebuah interaksi antara satu atau lebih aktor dengan sistem informasi yang dibuat.

\section{b. Class Diagram}

Classs Diagram menggambarkan struktur sistem dari segi pendefinisian kelas-kelas yang akan dibuat untuk membangun sistem. Kelas memiliki apa yang disebut atribut dan metode atau operasi.

\section{c. Sequence Diagram}

Sequence diagram menggambarkan kelakuan objek pada use case dengan mendeskripsikan waktu hidup objek dan message yang dikirim dan diterima antar objek.

\section{d. Activity Diagram}

Diagram aktifitas atau activity diagram menggambarkan workflow (aliran kerja) atau aktivitas dari sebuah sistem atau proses bisnis. Yang perlu diperhatikan disini adalah bahwa diagram aktivitas menggambarkan aktor, jadi aktivitas yang dapat dilakukan oleh sistem. 


\subsection{Defenisi Artificial Intelegence}

Artificial intelligence atau dalam bahasa Indonesianya kecerdasan buatan secara umum dapat diartikan sebagai ilmu komputer yang mempelajari bagaimana membuat sebuah mesin (komputer) dapat melakukan pekerjaan sebaik apa yang dilakukan oleh manusia bahkan lebih baik dari apa yang dikerjakan oleh manusia. Banyak pengertian atau definisi dari kecerdasan buatan ini yang dikemukakan oleh para ahli.

Carthy (dalam Dahria, 2008) menjelaskan tujuan dari artificial intelligence atau kecerdasan buatan itu adalah untuk memodelkan dan mengetahui proses-proses berpikir manusia dan mendesain mesin untuk menirukan cara berpikir manusia tersebut. Sementara Simon (dalam Dahria, 2008) menyatakan bahwa kecerdasan buatan atau artificial intelligence merupakan kawasan penelitian, aplikasi, dan instruksi yang terkait dengan pemrograman komputer untuk melakukan suatu hal yang dalam pandangan manusia adalah cerdas, selanjutnya, Rich and Knight (dalam Dahria, 2008) menjelaskan kecerdasan buatan ini sebagai sebuah studi tentang bagaimana membuat sebuah komputer melakukan hal-hal yang pada saat ini dapat dilakukan lebih baik oleh manusia.

\subsection{Konsep Dasar Searching}

Artificial intelligence (AI) sebagai suatu studi khusus yang tujuannya adalah membuat komputer berpikir dan bertindak seperti manusia. Implementasi AI sangat banyak di dalam bidang komputer, misalnya Decision Support Sistem (Sistem Pendukung Keputusan), Robotic, Natural Language (Bahasa Alami), Neural Network (Jaringan Saraf), dan lain-lain.

Contoh bidang lain pengembangan kecerdasan buatan ini adalah searching. Searching (pencarian) menggabungkan pengetahuan dan penelusuran data untuk memecahkan masalah yang secara normal memerlukan keahlian manusia. Tujuan pengembangan searching ini sebenarnya untuk membantu pengguna menemukan jalan tercepat/terpendek, sehingga dapat digunakan oleh orang banyak untuk mengefisiensi waktu dan jarak tempuh dari suatu tempat ketempat tujuan. Searching adalah Suatu proses mencari solusi dari suatu permasalahan melalui sekumpulan kemungkinan ruang keadaan (state space). Ruang keadaan merupakan suatu ruang yang berisi semua keadaan yang mungkin.

\subsection{Algoritma Dijkstra}

Algoritma Dijkstra dinamai sesuai dengan nama penemunya yaitu Edsger Dijkstra. Algoritma Dijkstra menggunakan prinsip greedy, dimana pada setiap langkah dipilih sisi dengan bobot minimum yang menghubungkan sebuah simpul yang sudah terpilih dengan simpul lain yang belum terpilih [8] . Input algoritma ini adalah sebuah graf berarah dan berbobot, $G$ dan sebuah source vertex s dalam G. V adalah himpunan semua simpul dalam graph G. Setiap sisi dari graph ini adalah pasangan vertices $(\mathrm{u}, \mathrm{v})$ yang melambangkan hubungan dari vertex $\mathrm{u}$ ke vertex v. Himpunan semua edge disebut $\mathrm{E}$. Weights dari edges dihitung dengan fungsi $\mathrm{w}: \mathrm{E} \rightarrow[0, \infty]$; jadi $\mathrm{w}(\mathrm{u}, \mathrm{v})$ adalah jarak non-negatif dari vertex u ke vertex v. Cost dari sebuah edge dapat dianggap sebagai jarak antara dua vertex, yaitu jumlah jarak semua edge dalam path tersebut. Untuk sepasang vertex $\mathrm{s}$ dan t dalam V, algoritma ini menghitung jarak terpendek dari s ke t. (Diana Okta Pugas dkk : 2011)

\section{Metodologi}

\subsection{Kerangka Penelitian}


Makna penelitian secara sederhana ialah bagaimana mengetahui sesuatu yang dilakukan melalui cara tertentu dengan prosedur yang sistematis. Maka penulis membentuk kerangka penelitian seperti gambar 3.1

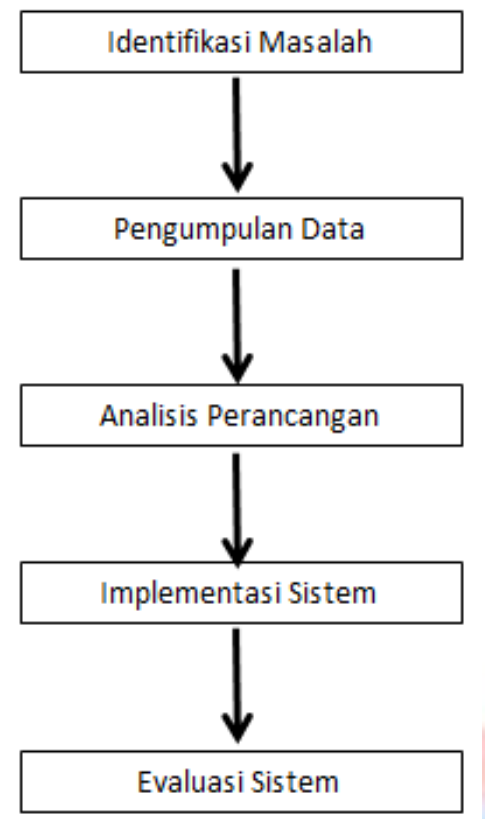

\section{Gambar 3.1 Kerangka Kerja Penelitian}

\section{a. Identifikasi Masalah}

Identifikasi masalah merupakan tahap awal dalam perancangan dan pengembangan sebuah sistem yang akan dirancang, karena pada tahap inilah akan diukur dan dievaluasi kinerja sistem yang dirancang. Identifikasi terhadap masalah-masalah yang ada dan langkah- langkah untuk kebutuhan perancangan yang diharapkan.

\section{b. Pengumpulan Data}

Pada metode ini penulis melakukan penenlitian untuk mendapatkan data primer dengan langsung terjun ke lapangan dan melakukan pencatatan data yang diperlukan serta mengumpulkan beberapa laporan yang diperlukan untuk dapat dijadikan pedoman dalam pembuatan skripsi ini dengan teknik pengumpulan data primer.

\section{c. Impelementasi}

Implementasi sistem merupakan bagian dari siklus hidup pengembangan sistem. Untuk melakukan sebuah implementasi maka diperlukan program komputer yaitu perancangan interface dan penulisa kode program sesuai dengan sistem yang dirancang. Pada tahap ini program sudah berjalan.

\section{d. Evaluasi}

Evaluasi juga dibutuhkan agar aplikasi yang dibuat sesuai dengan kebutuhan user, setelah memperlihatknnya pada user dan mempertanyakan apakah hasil rancangan dengan proses uji 
sistem telah dibuat sesuai dengan keperluan pengguna (user). Tujuan dari evaluasi yaitu untuk melihat seberapa tepat aplikasi yang dibuat sehingga sesuai dengan kebutuhan user, dan mengidentifikasi problem yang terjadi pada system.

\section{Hasil dan Diskusi}

\subsubsection{Daftar nama Kecamatan dan Desa/Kelurahan di Kota Padang}

Adapun data nama-nama kecamatan di Kota Padang dapat dilihat pada Tabel 4.1

Tabel 4.1 Nama-nama Kecamatan di Kota Padang

\begin{tabular}{|c|c|l|}
\hline No & Kode Kecamatan & \multicolumn{1}{c|}{ Nama Kecamatan } \\
\hline 1 & K001 & Kecamatan Bungus Teluk Kabung \\
\hline 2 & K002 & Kecamatan Kuranji \\
\hline 3 & K003 & Kecamatan Lubug Begalung \\
\hline 4 & K004 & Kecamatan Lubug Kilangan \\
\hline 5 & K005 & Kecamatan Padang Barat \\
\hline 6 & K006 & Kecamatan Padang Selatan \\
\hline 7 & K008 & Kecamatan Padang Timur \\
\hline 8 & K009 & Kecamatan Padang Utara \\
\hline 9 & K010 & Kecamatan Pauh \\
\hline 10 & &
\end{tabular}

Ada beberapa Desa/Kelurahan yang akan dilalui untuk sampai ke kecamatan yang dituju, antara lain dapat diuraikan pada Tabel 4.2

Tabel 4.2 Data Nama-nama Desa/Kelurahan di Kota Padang

\begin{tabular}{|c|c|}
\hline Kode & Nama-nama Desa/Kelurahan \\
\hline 1 & 2 \\
\hline DK01 & Desa/Kelurahan Bungus Barat \\
\hline DK02 & Desa/Kelurahan Bungus Selatan \\
\hline DK03 & Desa/Kelurahan Bungus Timur \\
\hline DK04 & $\begin{array}{lll}\text { Desa/Kelurahan } & \text { Teluk } & \text { Kabung } \\
\text { Selatan } & & \end{array}$ \\
\hline DK05 & $\begin{array}{l}\text { Desa/Kelurahan } \\
\text { Tengah }\end{array}$ \\
\hline
\end{tabular}


UPI YPTK Jurnal KomTekInfo Vol. 5, No. 1, Juni 2018, Hal. 48-57 ISSN :2356-0010 | eISSN :2502-8758 Copyright@2018 by LPPM UPI YPTK Padang

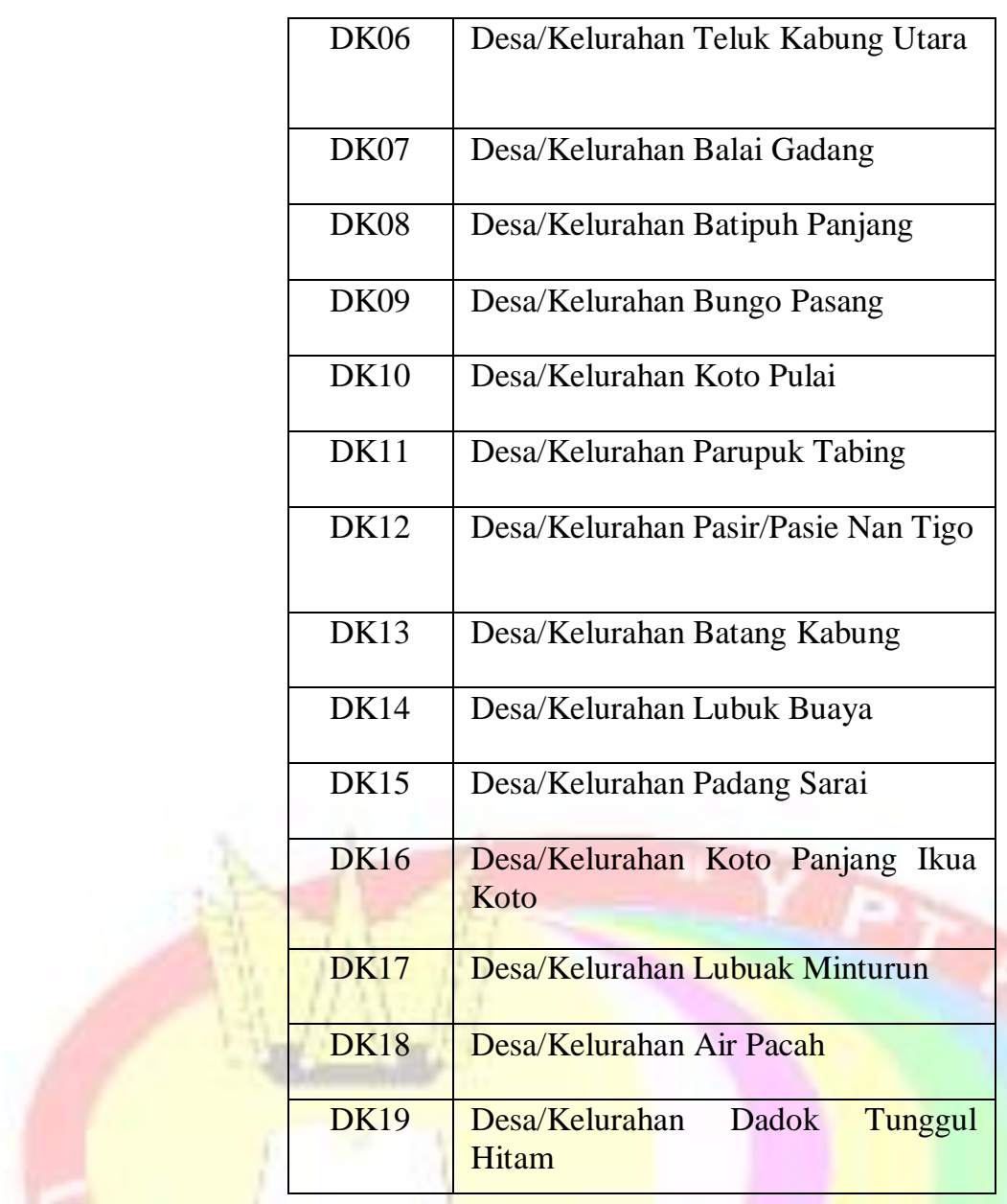

\subsubsection{Data Jarak Tiap Rute}

Adapun data jarak untuk rute kecamatan di Kota Padang dapat dilihat pada Tabel 4.3:

Tabel 4.3 Data Jarak Tiap Rute Antar Kecamatan Di Kota Padang

\begin{tabular}{|c|l|l|c|}
\hline \multirow{2}{*}{ No } & \multicolumn{1}{|c|}{ Kecamatan } & \multicolumn{1}{|c|}{ Link ke-Kecamatan } & Nilai/Beban \\
\hline \multirow{5}{*}{1} & \multirow{2}{*}{$\begin{array}{l}\text { Kecamatan Bungus Teluk } \\
\text { Kabung }\end{array}$} & Kecamatan Koto Tangah & $41 \mathrm{~km}$ \\
\cline { 3 - 4 } & & Kecamatan Kuranji & $26 \mathrm{~km}$ \\
\cline { 3 - 4 } & & Kecamatan Lubug Begalung & $18 \mathrm{~km}$ \\
\cline { 3 - 4 } & & Kecamatan Lubug Kilangan & $28 \mathrm{~km}$ \\
\cline { 3 - 4 } & & Kecamatan Nanggalo & $28 \mathrm{~km}$ \\
\cline { 3 - 4 } & & Kecamatan Padang Barat & $18 \mathrm{~km}$ \\
\cline { 3 - 4 } & & Kecamatan Padang Selatan & $20 \mathrm{~km}$ \\
\cline { 3 - 4 } & & Kecamatan Padang Timur & $21 \mathrm{~km}$ \\
\cline { 3 - 4 } & &
\end{tabular}


UPI YPTK Jurnal KomTekInfo Vol. 5, No. 1, Juni 2018, Hal. 48-57 ISSN :2356-0010 | eISSN :2502-8758 Copyright@2018 by LPPM UPI YPTK Padang

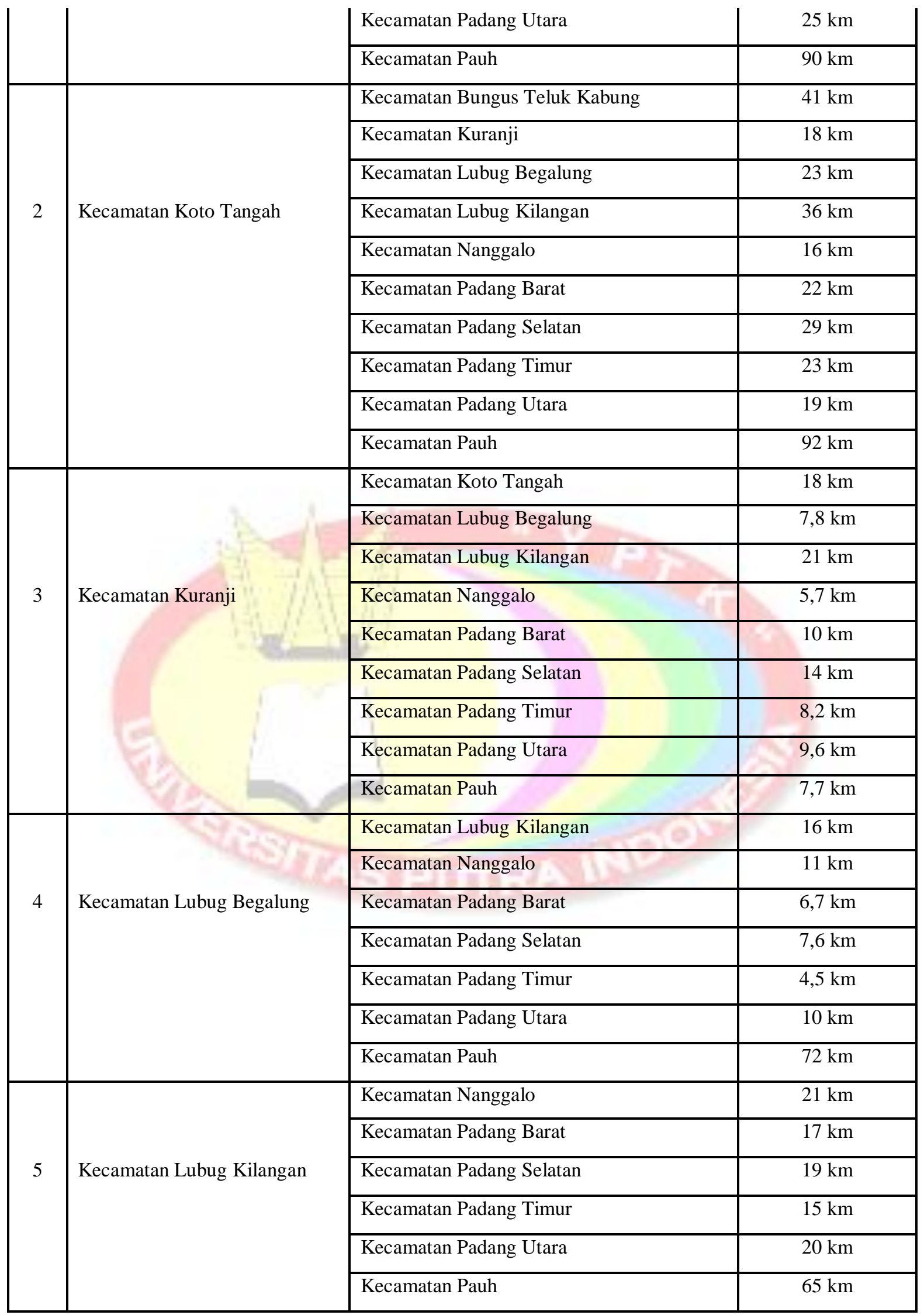


Contoh perhitungan manual pencarian rute dari Kecamat Bungus Teluk Kabung ke Kecamatan Padang Barat.

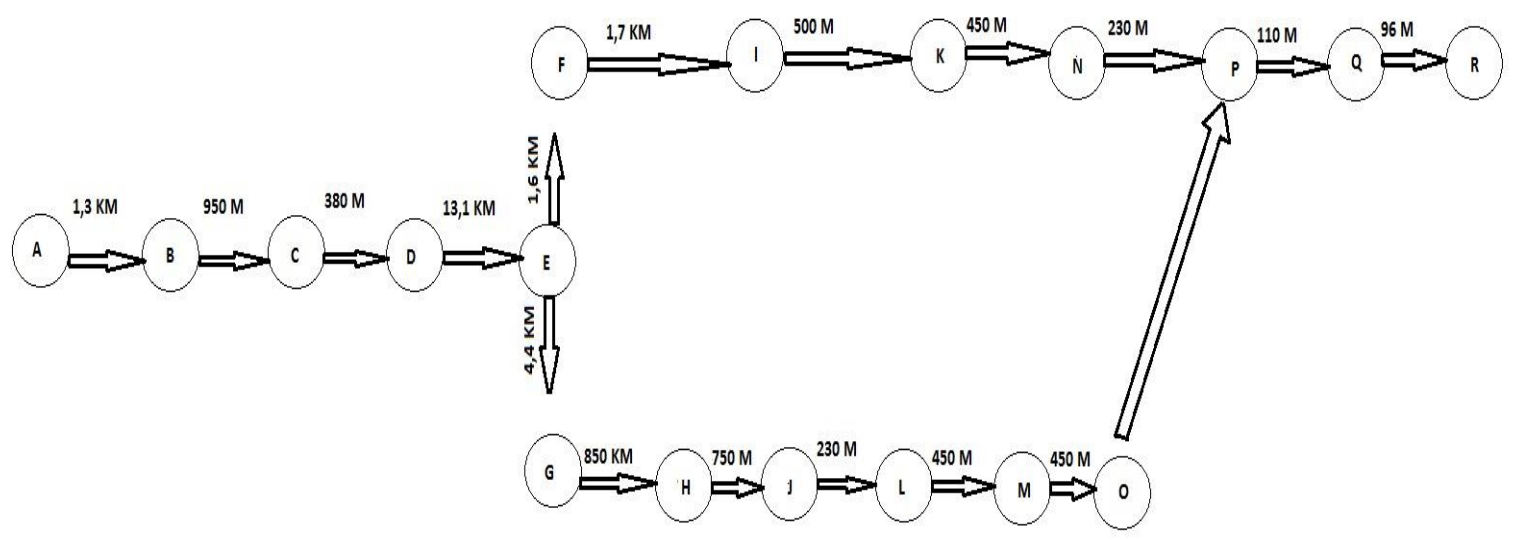

Gambar 4.1 ilustrasi jarak kecamatan bungus ke kecamatan padang barat.

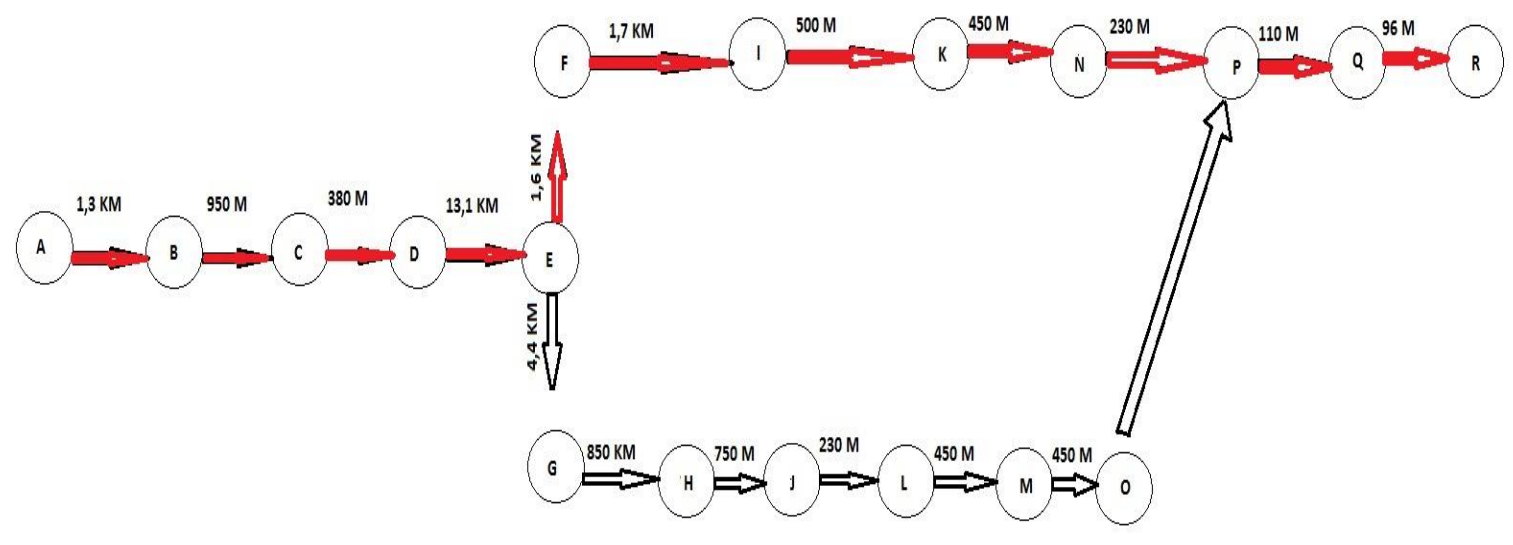

Gambar 4.2 Hasil Akhir Pencarian Rute

\subsection{Analisa Kebutuhan Fungsional dan Perancangan}

Analisa kebutuhan fungsional menggambarkan proses kegiatan yang akan diterapkan dalam sistem dan menjelaskan kebutuhan yang diperlukan agar sistem dapat berjalan dengan baik serta sesuai dengan kebutuhan. Analisa yang dilakukan dimodelkan dengan menggunakan UML (Unified Modeling Language). Tahapan pemodelan dalam analisis tersebut anatara lain mengindentifikasikan aktor, pembuatan diagram, dan scenario.

\section{Activity Diagram User}

Activity diagram user menggambarkan segala aktivitas yang bisa dilakukan oleh user terhadap sistem yang dimulai dengan memasukan kecamatan awal, dan kecamatan tujuan untuk menghasilkan output. Acitivity diagram pada user dapat dilihat pada gambar di 4.1 : 
UPI YPTK Jurnal KomTekInfo Vol. 5, No. 1, Juni 2018, Hal. 48-57 ISSN :2356-0010 | eISSN :2502-8758 Copyright $\odot 2018$ by LPPM UPI YPTK Padang

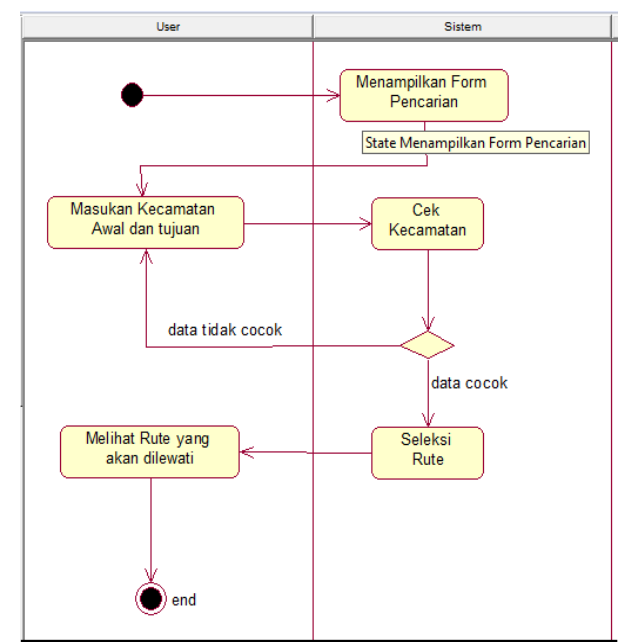

Gambar 4.3 Activity Diagram User

\subsection{Implementasi Sistem}

Layaout awal merupakan tampilan pertama yang akan dijumpai saat akan menggunakan aplikasi. Layout awal terdiri dari daftar kecamatan, pencarian rute, petunjuk penggunaan, about, keluar, seperti pada gambar 5.28 berikut :

\section{A. Layout Awal Program}

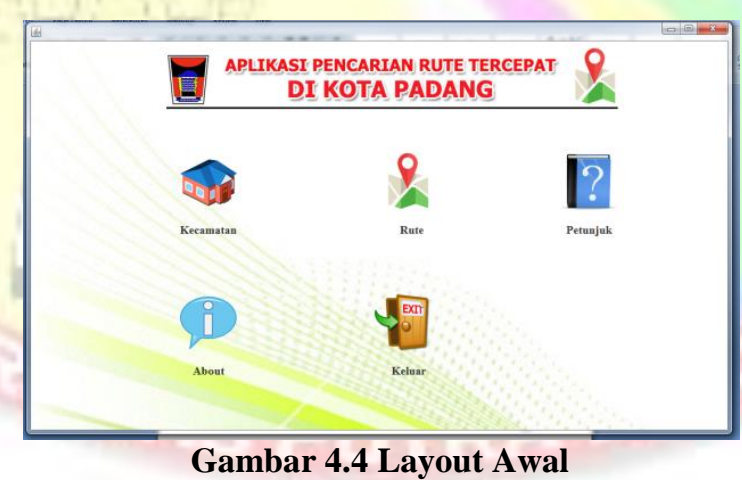

\section{B. Layout Kecamatan}

Layout Kecamatan merupakan daftar dari kecamatan yang ada dikota padang yang dapat dilihat pada gambar 4.5 dibawah ini:

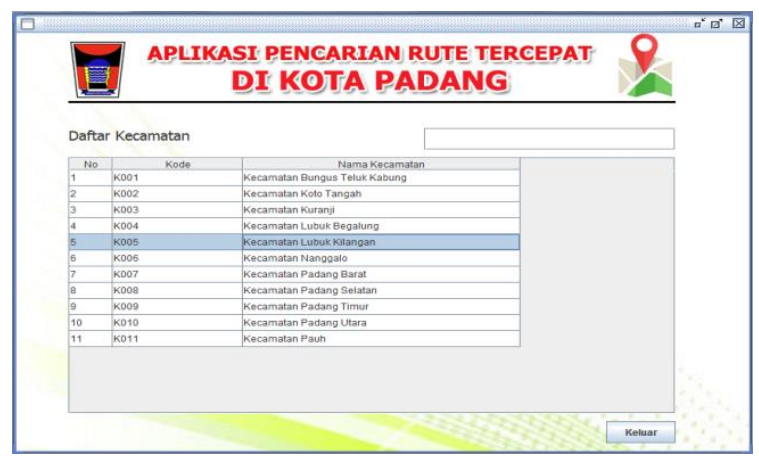

Gambar 4.5 Layout Kecamatan 


\section{Layout Pencarian Rute}

Layout pencarian rute ini merupaka layout yang nantinya akan digunakan untuk mencari rute yang akan dilewati oleh pengguna untuk mencapai tujuan. Layout pencarian rute ini dapat dilihat pada gambar 4.6 berikut:

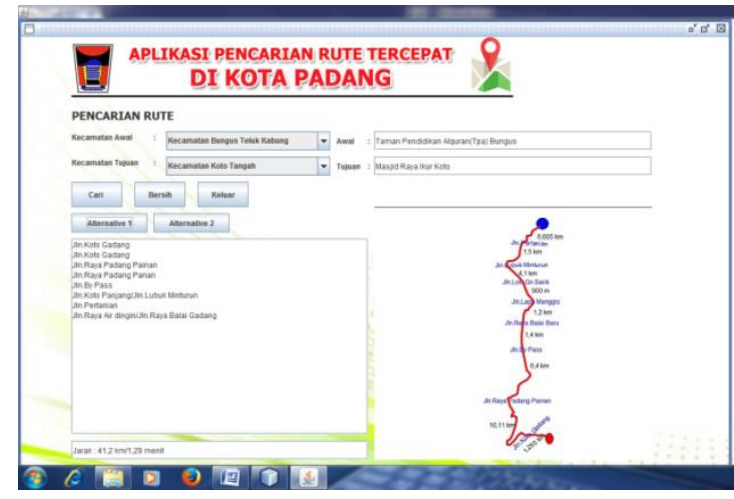

Gambar 4.6 Layout Pencarian Rute

\section{Kesimpulan}

Berdasarkan penelitian ini penulis menarik kesimpulan bahwa :

1. Dari Aplikasi Pencarian Rute Tercepat ini, terlihat bahwa pengguna memilih Kecamatan Awal dan Kecamatan Tujuan sehingga pengguna dapat melihat daerah yang akan dilewati.

2. Dengan adanya Aplikasi Pencarian Rute Tercepat ini, pengguna dapat lebih menghemat waktu perjalanan dengan memilih alternatif yang akan dilewati dengan jarak dan waktu tempuh yang berbeda.

3. Dari Aplikasi ini, pengguna dapat membuat keputusan jalan mana yang akan di tempuh untuk sampai ketempat tujuan dengan waktu yang sedikit.

\section{Referensi}

[1] A.S, Rosa, Shalahuddin, M. (2015). Rekayasa Perangkat Lunak. Bandung: Informatika Bandung

[2] Bambang, Heriyanto. (2014). Bahasa Pemograman Java. Bandung: Informatika Bandung

[3] R. Mulyanto, Aunur. (2008). Rekayasa Perangkat Lunak. Jakarta: Direktorat Pembina Sekolah Kejuruan dan Direktorat Pembina Manajemen Dasar dan Menengah

[4] Rusel, dkk. (1995). Artificial Intelegence A Modern Approach

[5] Sutojo, dkk. (2011).Kecerdasan Buatan.Yogyakarta: C.V Andi Ofset 